\title{
Assessment of nasal and sinus nitric oxide output using single-breath humming exhalations
}

\author{
M. Maniscalco*,\#, E. Weitzberg", J. Sundberg ${ }^{+}$, M. Sofia\#, J.O. Lundberg*
}

Assessment of nasal and sinus nitric oxide output using single-breath humming exhalations. M. Maniscalco, E. Weitzberg, J. Sundberg, M. Sofia, J.O. Lundberg. (C) ERS Journals Ltd 2003.

ABSTRACT: Nasal nitric oxide (NO) levels increase greatly during humming compared to silent exhalation. In this study, the physiological and anatomical factors that regulate NO release during humming have been characterised in 10 healthy subjects and in a model of the sinus and the nose.

Single-breath humming caused a large initial peak in nasal NO output, followed by a progressive decline. The NO peak decreased in a step-wise manner during repeated consecutive humming manoeuvres but recovered completely after a silent period of $3 \mathrm{~min}$. Topical nasal application of an NO synthase inhibitor reduced nasal NO by $>\mathbf{5 0} \%$ but had no effect on the increase evoked by humming. Silently exhaled nasal NO measured immediately after repeated humming manoeuvres was between 5-50\% lower than basal silent NO exhalation, suggesting variable continuous contribution from the sinuses to nasal NO. Among the factors known to influence normal sinus ventilation, ostium size was the most critical during humming, but humming frequency was also of importance.

In conclusion, humming results in a large increase in nasal nitric oxide, which is caused by a rapid gas exchange in the paranasal sinuses. Combined nasal nitric oxide measurement with and without humming could be of use to estimate sinus ventilation and to better separate nasal mucosal nitric oxide output from sinus nitric oxide in health and disease.

Eur Respir J 2003; 22: 323-329.
*Dept of Physiology and Pharmacology, Karolinska Institutet, $\uparrow^{-D e p t}$ of Anesthesiology and Intensive Care, Karolinska Hospital and ${ }^{+}$Dept of Speech Music and Hearing, Royal Institute of Technology, Stockholm, Sweden. " Dept of Respiratory Medicine, University Federico II, Naples, Italy.

Correspondence: J.O. Lundberg, Dept of Physiology and Pharmacology, 17177 Karolinska Institutet, Stockholm, Sweden.

Fax: 468332278

E-mail: jon.lundberg@fyfa.ki.se

Keywords: Asthma, exhaled nitric oxide, nasal, rhinitis, sinusitis

Received: February 172003

Accepted after revision: April 242003

This study was supported by a grant from the Swedish Heart-Lung Foundation, the Swedish Research Council and by a grant from University Federico II "Progetto scambi internazionali".
Nitric oxide (NO) is released into the airway lumen [1], in particular in the upper airways [2-4]. The exact origin of NO found in nasal air and the relative contribution from different sources within the nasal airways are not known. The paranasal sinuses are major sources of NO in adult healthy subjects [5] and the concentrations in a healthy sinus may be very high, ranging 5-20 parts per million (ppm) [5]. The sinuses communicate with the nasal cavity through the ostia and the rate of gas exchange between these cavities is dependent on several factors, such as the size of the ostia, the volume of the sinus, the nasal airflow and intra-nasal pressure [6, 7]. Proper ventilation is essential for maintenance of sinus integrity, and blockage of the ostium is a central event in the pathogenesis of sinusitis [8,9]. During normal ventilation, the time required to exchange all air in the sinuses is $\sim 30 \mathrm{~min}$, with large inter-individual variation $[7,10]$. Sinus ventilation is much slower in patients with sinus disorders [10].

Recently, the current authors have shown that nasal NO levels increase greatly during humming compared to normal silent nasal exhalation, probably by speeding up the sinus gas exchange, thereby increasing nasal NO output [11]. In a twocompartment model of the nose and sinus the authors demonstrated that pulsating airflow, created by humming, causes a dramatic increase in gas exchange between these cavities [11].

In the current study the authors wanted to further characterise nasal NO during humming, and to explore the various factors that determine gas exchange between the sinuses and the nasal cavity. Moreover, they wanted to investigate if NO measurements during humming could give additional information about the NO production at different sites in the upper airways. This was achieved by studying healthy volunteers, as well as creating a model of the sinus and the nose, where the influence on NO output by ostium size, humming frequency, sinus volume, sinus NO concentration, air flow and pressure could be investigated. The study was approved by the local ethics committee.

\section{Materials and methods}

\section{Sinus/nasal model}

Description of the model. NO output was measured in a twocompartment model resembling the nasal cavity and one sinus (fig. 1). A syringe (representing the sinus) was filled with various NO gas concentrations ranging 2-10 ppm (AGA AB, Stockholm, Sweden) and connected horizontally to a plastic cylinder (representing the nasal cavity) via a luer fitting. The diameter of the syringe tip (representing the ostium) was varied between $0.8-4.0 \mathrm{~mm}$. The volume of the syringe was varied between 5-20 mL. The distal end of the cylinder (nasal cavity) was left open or connected to a Hans Rudolph resistor of $50 \mathrm{cmH}{ }_{2} \mathrm{O} \cdot \mathrm{L}^{-1} \cdot \mathrm{s}^{-1}$, thereby generating cylinder pressures of either 1 or $10 \mathrm{cmH}_{2} \mathrm{O}$. Flow and pressure were measured by a linear pneumotachymeter (Hans Rudolph Inc., KS, USA). 


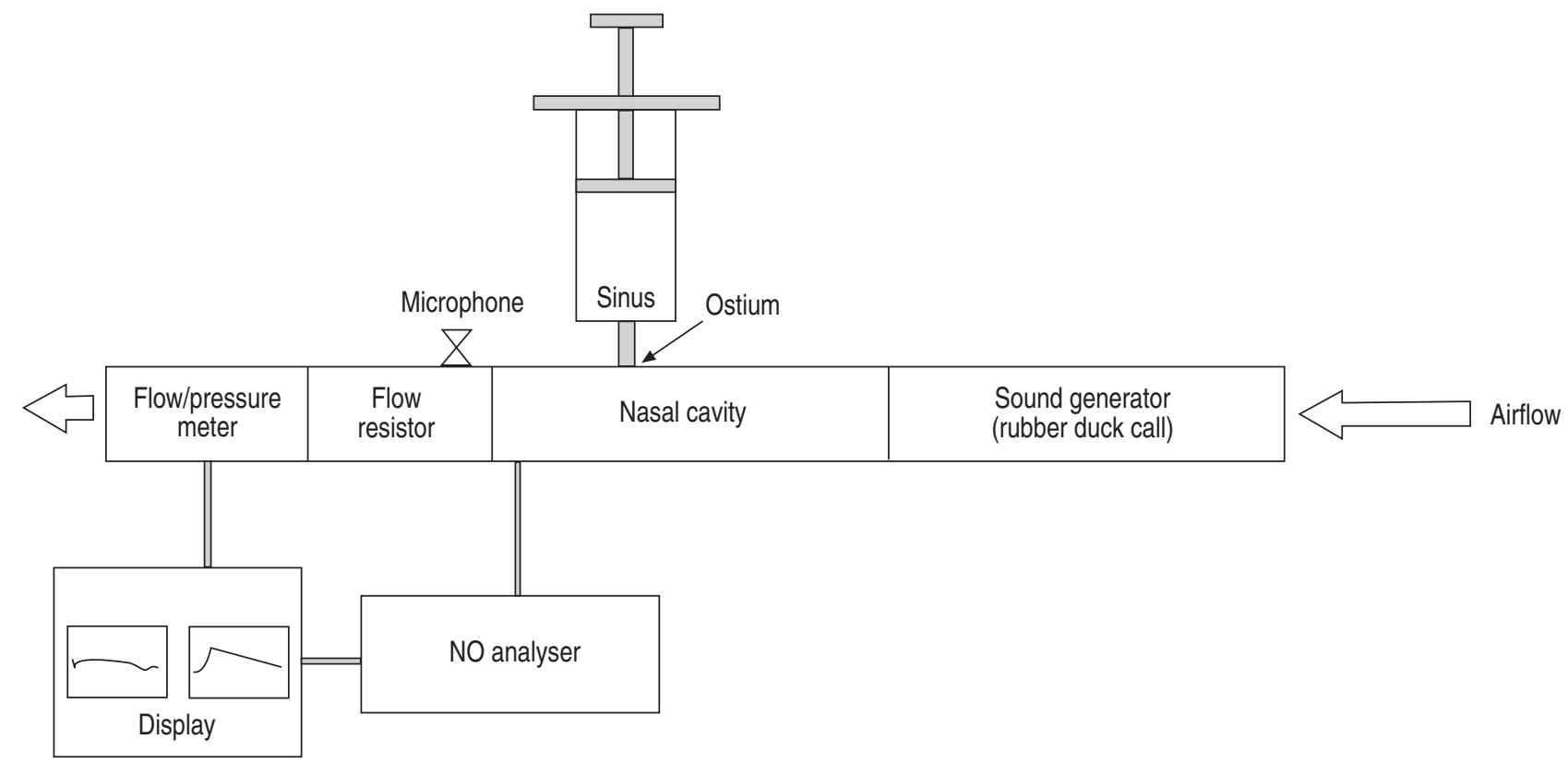

Fig. 1. - Schematic presentation of a model resembling the sinus (syringe), the ostium (syringe tip) and the nasal cavity (plastic cylinder). NO: nitric oxide.

Resulting NO output was measured at the distal end of the cylinder by a rapid-response chemiluminescence system (Aerocrine AB, Stockholm, Sweden). The signal output from these devices were connected to a computer-based system (Aerocrine NO system; Aerocrine AB) and yielded an instant on-screen display of flow, pressure, $\mathrm{NO}$ concentration and NO output.

Artificial generation of humming in the model. Pressurised NO-free air was set to generate three different flow rates $(0.20$, 0.25 and $\left.0.30 \mathrm{~L} \cdot \mathrm{s}^{-1}\right)$. The air was led through the plastic cylinder (nasal cavity) either via a rubber duck call (Hudson \& Co., London, UK), which yielded a pulsating airflow, or via a rubber duck call without the sound generating membrane (quiet control). Three duck calls with different fundamental frequencies $(120,200$ and $450 \mathrm{~Hz})$ were used. NO was measured during a 10-s period and all experiments were repeated five times. In an additional experiment, a turbulent flow was generated by leading pressurised NO-free air through a plastic mesh connected to the cylinder and NO was measured as described above. This experiment was carried out without a sound-generating device.

In a separate experiment, the effect of three different humming frequencies $(120,200$ and $450 \mathrm{~Hz})$ on NO output from sinuses with different resonance frequencies (120 or $200 \mathrm{~Hz}$ ) were studied.

Human humming in the model. In the same model, the pulsating airflow was also generated by a subject performing oral exhalation through the cylinder, with or without phonation, at two fixed flow rates $\left(0.20\right.$ or $\left.0.25 \mathrm{~L} \cdot \mathrm{s}^{-1}\right)$ and three different frequencies $(130,150$ or $450 \mathrm{~Hz})$. NO output was calculated from the entire exhalation $(10 \mathrm{~s})$ with subtraction of oral NO output. All experiments were repeated five times. To estimate the rate of NO exchange between the two cavities, the remaining NO concentration in the syringe at the end of each experiment was also measured.

Measurement of artificial and human humming sound frequency. The audio signal of humming was picked up by a TCM 110 Tiepin electret condenser microphone placed on the plastic cylinder in the model (fig. 1) and recorded directly onto a PC by the Soundswell Signal Workstation. The fundamental frequency was extracted by its Corr module, which computes the autocorrelation of the audio signal in two adjacent time windows. The mean fundamental frequency and SD were then determined by means of its histogram module.

The resonance frequency of the model system was calculated according to DURRANT and LOVRINIC [12].

\section{In vivo studies}

Characterisation of nasal nitric oxide during humming. A total of 10 healthy nonsmoking volunteers (aged 25-47 yrs, six males) without any history of allergy, nasal disease, asthma or any other chronic lung conditions were recruited. Airway NO output was measured with a chemiluminescence system (NIOX; Aerocrine AB) designed to meet the American Thoracic Society guidelines for exhaled NO [13]. The analyser was calibrated with standard gas mixtures of $\mathrm{NO}$ (987 parts per billion; AGA AB).

NO output was measured during oral and nasal singlebreath exhalations. A tight-fitting mask covering the nose was used for nasal measurements and a mouthpiece was used for oral exhalations. The subjects started each manoeuvre by inhaling NO-free air through the nose and then exhaled at a fixed flow rate $\left(0.20 \mathrm{~L} \cdot \mathrm{s}^{-1}\right)$ for $10 \mathrm{~s}$ either quietly or with nasal humming or oral phonation. The fixed flow rate was achieved by a dynamic flow restrictor in the analysing system, combined with a computerised visual feed back display of flow. The dynamic flow restrictor uses an elastic membrane valve to mechanically adjust flow rate and keep exhalation at $0.20 \mathrm{~L} \cdot \mathrm{s}^{-1}$ within a wide range of exhalation pressures with minimal variation.

Nasal NO output during humming was calculated by subtracting the values obtained during silent oral exhalations as described earlier $[14,15]$. NO was calculated as the mean output $\left(\mathrm{nL} \cdot \mathrm{min}^{-1}\right)$ during the last $80 \%$ (i.e. $8 \mathrm{~s}$ ) of the exhalation.

To investigate if humming could exhaust the source of NO, the subjects performed five consecutive humming manoeuvres 
with different time intervals ( $5 \mathrm{~s}, 1$ and $3 \mathrm{~min}$ ) between each humming. In addition, repeated silent nasal exhalations were performed at 5-s intervals. Based on the results obtained from consecutive humming manoeuvres (see below), all other humming exhalations in this study were preceded by a 3 -min period of silence.

Effects of nitric oxide synthase inhibition. In six of the subjects, baseline nasal and oral NO measurements were performed both during humming and silent exhalations. Subsequently, either a solution of $N^{\mathrm{G}}$-L-arginine methyl ester (L-NAME) (Sigma, Poole, UK), $15 \mathrm{mg}(22 \mathrm{mM})$ in $2.5 \mathrm{~mL}$ of saline, or saline alone was delivered through both nostrils by a jet nebuliser (Devilbiss, Somerset, PA, USA) and the NO measurements were repeated $20 \mathrm{~min}$ after application of the solutions.

Effects of flow, pressure and frequency during humming. To compare the results from the model described above to the in vivo situation, additional experiments were performed in five of the subjects. The subjects were asked to exhale in turn at two fixed flow rates $\left(0.20\right.$ and $\left.0.25 \mathrm{~L} \cdot \mathrm{s}^{-1}\right)$ against no resistance or at a resistance of $50 \mathrm{~cm} \mathrm{H} \mathrm{H}_{2} \cdot \mathrm{L}^{-1} \cdot \mathrm{s}^{-1}$ for a period of $10 \mathrm{~s}$ either silently or with nasal humming or oral phonation. This was followed by nasal humming manoeuvres at three different sound frequencies. Frequency was registered with the microphone taped to the neck of the subject.

\section{Calculations and statistics}

The NO output was calculated for all sampling modalities as flow $\times \mathrm{NO}$ concentration. In the analysers used (Aerocrine $\mathrm{AB}$ ) this calculation is made every $100 \mathrm{~ms}$ in real time during the exhalation and is expressed as $\mathrm{nL} \cdot \mathrm{min}^{-1}$. Nonparametric statistics with two-way p-values were used. For analysis of paired data Friedman's test and Wilcoxon's test were used. A $\mathrm{p}<0.05$ was considered significant. Results are presented as mean \pm SEM.

\section{Results}

\section{In vivo studies}

In all humming experiments, an initial NO peak was observed followed by a progressive decline (fig. 2). Total nasal NO output increased during humming, as compared to

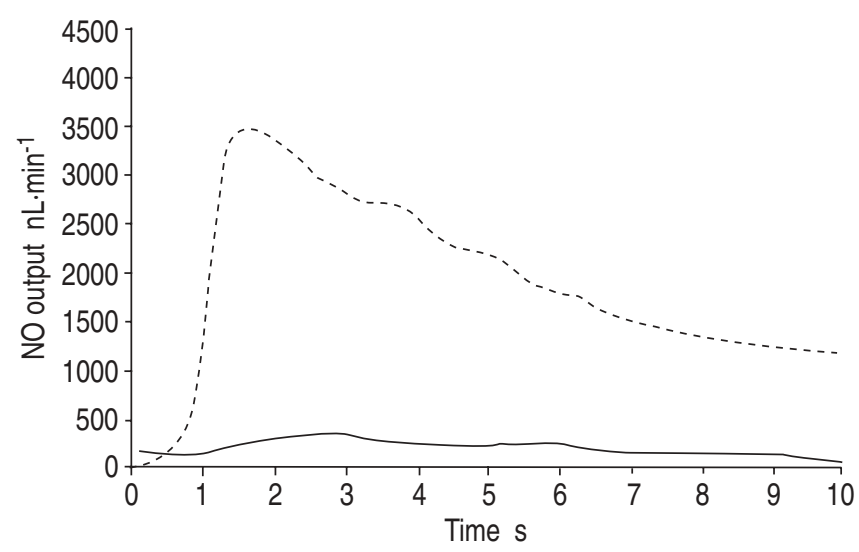

Fig. 2.-Original tracing of nitric oxide (NO) during a single-breath nasal exhalation with humming (----) or silently (-).

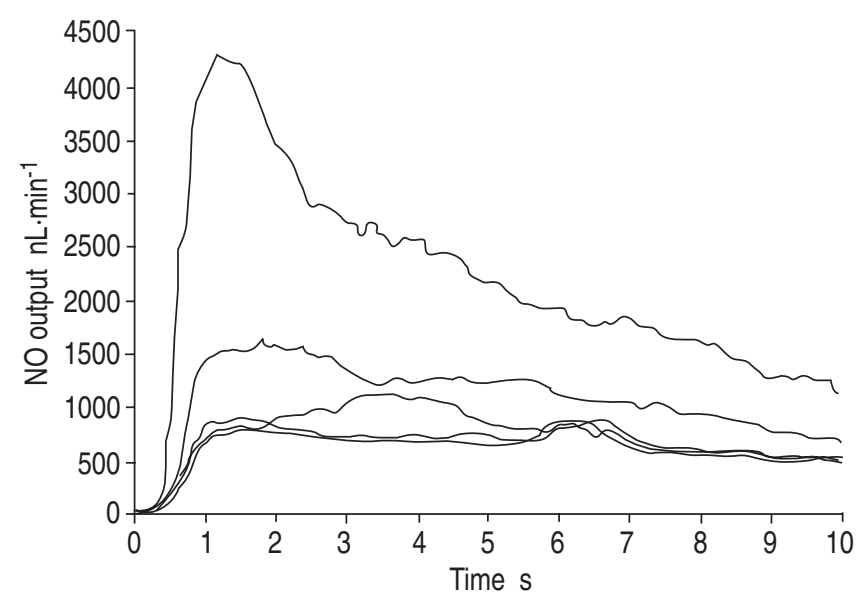

Fig. 3. - Effect of repeated humming manoeuvres on nasal nitric oxide (NO) output. Five consecutive exhalations with humming were performed at 5-s intervals. A progressive reduction in NO output was observed after each manoeuvre until a plateau was reached.

silent exhalation (from $471 \pm 73 \mathrm{~nL} \cdot \mathrm{min}^{-1}$ during silent exhalation to $2,233 \pm 467 \mathrm{~nL} \cdot \mathrm{min}^{-1}$ during humming; $\mathrm{p}<$ 0.001 ) (fig. 2). Orally exhaled NO was $144 \pm 20 \mathrm{~nL} \cdot \mathrm{min}^{-1}$ with silent exhalation and $152 \pm 20 \mathrm{~nL} \cdot \mathrm{min}^{-1}$ with phonation $(\mathrm{p}=0.22)$.

NO output measured during five single-breath humming manoeuvres with 3-min intervals between each humming was similar, showing an intra-individual variability of $<15 \%$. With 1-min intervals, the intra-individual variability was nearly $70 \%$. With 5-s intervals, NO decreased progressively after each manoeuvre until a stable plateau was reached at a level of $571 \pm 88 \mathrm{~nL} \cdot \mathrm{min}^{-1}$, as compared to levels during the first humming of $2,233 \pm 467 \mathrm{~nL} \cdot \mathrm{min}^{-1}, \mathrm{p}=0.002$ (fig. 3). In all subjects the low plateau was reached within four nasal humming manoeuvres. In contrast, five consecutive silent nasal exhalations with 5-s intervals did not affect NO output (fig. 4). However, silent nasal NO output measured immediately after repeated humming manoeuvres was lower than basal silent NO output in all subjects $\left(261 \pm 35 \mathrm{~nL} \cdot \mathrm{min}^{-1}\right.$ versus $\left.384 \pm 39 \mathrm{~nL} \cdot \mathrm{min}^{-1} ; \mathrm{p}=0.021\right)$. There was a substantial variability in the reduction of silent nasal NO output after

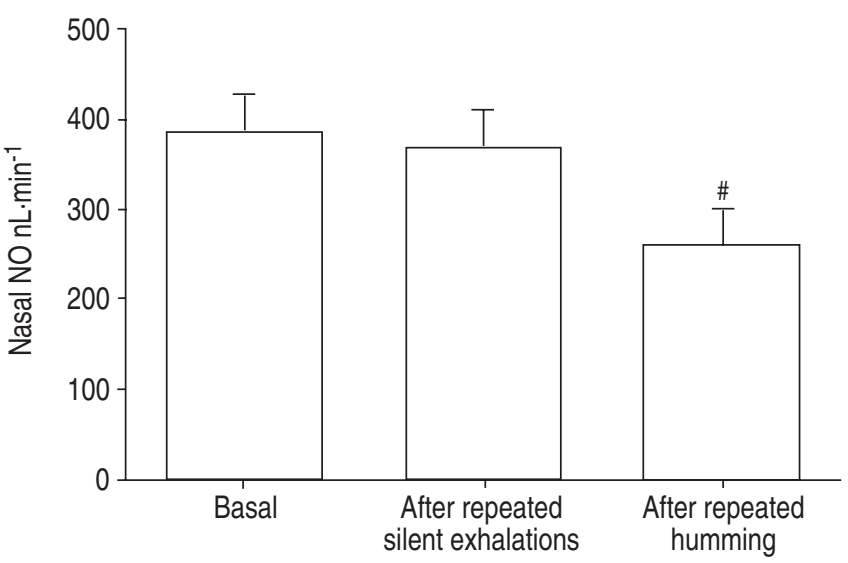

Fig. 4. - Nasal nitric oxide (NO) output measured during a silent exhalation at baseline, immediately after repeated silent nasal exhalations and immediately after repeated humming manoeuvres (five consecutive 10 -s nasal exhalations with humming). ${ }^{\#}$ : $\mathrm{p}=0.002$, as compared to baseline, $\mathrm{n}=6$. 


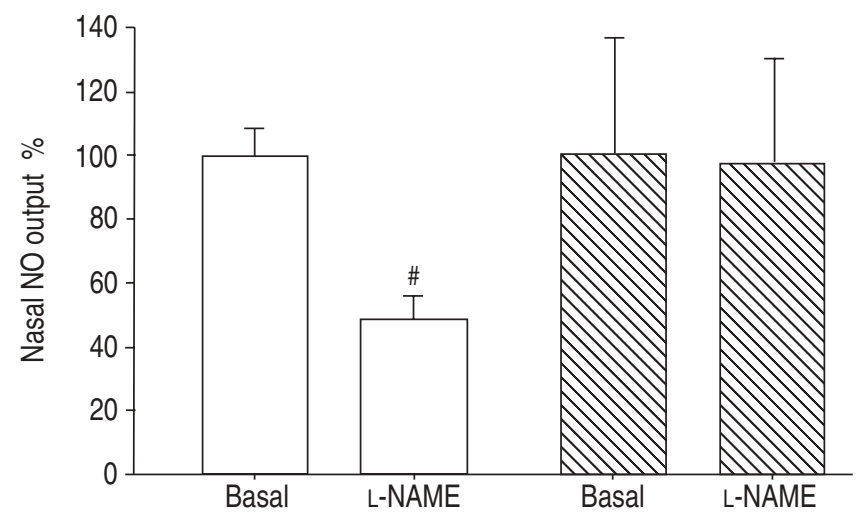

Fig. 5. - Change in nasal nitric oxide (NO) output after topical nasal application of an NO synthase inhibitor (L-NAME). The subjects exhaled either silently $(\square)$ or with humming $(\mathbb{\mathbb { Q }})$. ${ }^{\#}$ : $\mathrm{p}=0.002, \mathrm{n}=6$.

consecutive humming ranging from 5-50\%. Topical application of L-NAME reduced silently exhaled nasal NO output by $>50 \%$, from $392 \pm 33 \mathrm{~nL} \cdot \mathrm{min}^{-1}$ to $194 \pm 24 \mathrm{~nL} \cdot \mathrm{min}^{-1}$ ( $\mathrm{p}=0.002$; fig. 5). In contrast, the humming-induced increase in NO output was not affected $\left(2417 \pm 894 \mathrm{~nL} \cdot \mathrm{min}^{-1}\right.$ before L-NAME versus $2368 \pm 811 \mathrm{~nL} \cdot \mathrm{min}^{-1}$ after L-NAME; $\left.\mathrm{p}=0.77\right)$.

Effects of flow, pressure and frequency during humming. Increasing the exhalation flow rate during humming from 0.20 to $0.25 \mathrm{~L} \cdot \mathrm{s}^{-1}$ resulted in higher nasal NO output (from $807 \pm 172$ to $\left.1074 \pm 197 \mathrm{~nL} \cdot \mathrm{min}^{-1} ; \mathrm{p}<0.05\right)$.

Change of humming frequency also affected nasal NO output. NO output was $940 \pm 77 \mathrm{~nL} \cdot \mathrm{min}^{-1}$ at $130 \mathrm{~Hz}, 807 \pm$ $77 \mathrm{~nL} \cdot \mathrm{min}^{-1}$ at $150 \mathrm{~Hz}$ and $719 \pm 58 \mathrm{~nL} \cdot \mathrm{min}^{-1}$ at $450 \mathrm{~Hz}$ $(\mathrm{p}<0.05)$. It increased with higher nasal pressure during humming (from $807 \pm 77 \mathrm{~nL} \cdot \mathrm{min}^{-1}$ at $1 \mathrm{cmH}_{2} \mathrm{O}$ to $932 \pm$ $26 \mathrm{~nL} \cdot \mathrm{min}^{-1}$ at $\left.10 \mathrm{cmH}_{2} \mathrm{O} ; \mathrm{p}>0.05\right)$.

\section{Sinus/nasal model}

In the standard setting of the model, a fixed flow rate of $0.2 \mathrm{~L} \cdot \mathrm{s}^{-1}$, a NO concentration of $8 \mathrm{ppm}$, a pressure of $1 \mathrm{cmH}_{2} \mathrm{O}$, a syringe volume of $15 \mathrm{~mL}$, an ostium size of $1.9 \mathrm{~mm}$ and a humming frequency of $200 \mathrm{~Hz}$ were used. The resonance frequency of this system was calculated to be $200 \mathrm{~Hz}$. When changing one parameter in the experiments, all other values were kept constant.

In all experiments using the model, artificial and human humming caused an increase in NO output compared to silent exhalation. When using artificial humming in the model, NO output increased $>10$-fold from $23.7 \pm 0.1 \mathrm{~nL} \cdot \mathrm{min}^{-1}$ during silent airflow to $295 \pm 4.5 \mathrm{~nL} \cdot \mathrm{min}^{-1}$ during humming $(\mathrm{p}<0.05)$. When a subject was humming in the model, NO output increased from $27.7 \pm 0.1 \mathrm{~nL} \cdot \mathrm{min}^{-1}$ during silent exhalation to $175 \pm 8 \mathrm{~nL} \cdot \mathrm{min}^{-1}(\mathrm{p}<0.05)$. No difference in NO output was seen in the model when using a turbulent flow compared to a nonturbulent flow $\left(25.2 \pm 0.2 \mathrm{~nL} \cdot \mathrm{min}^{-1}\right.$ and $23.7 \pm$ $0.1 \mathrm{~nL} \cdot \mathrm{min}^{-1}$, respectively).

Effect of ostium size. Ostial diameters of $0.8,1.3,1.9,2.1$ and $4.0 \mathrm{~mm}$ were used. NO output during humming increased with larger ostium size (fig. 6). With a ratio for the ostium size of $1: 1.6: 2.4: 2.6: 5$ the ratios for NO output in the human and artificial models were 1:4.5:6:14:30 and 1:8:13:15:39, respectively.

As an estimation of the rate of air exchange in the sinus, the remaining NO concentration in the syringe was measured

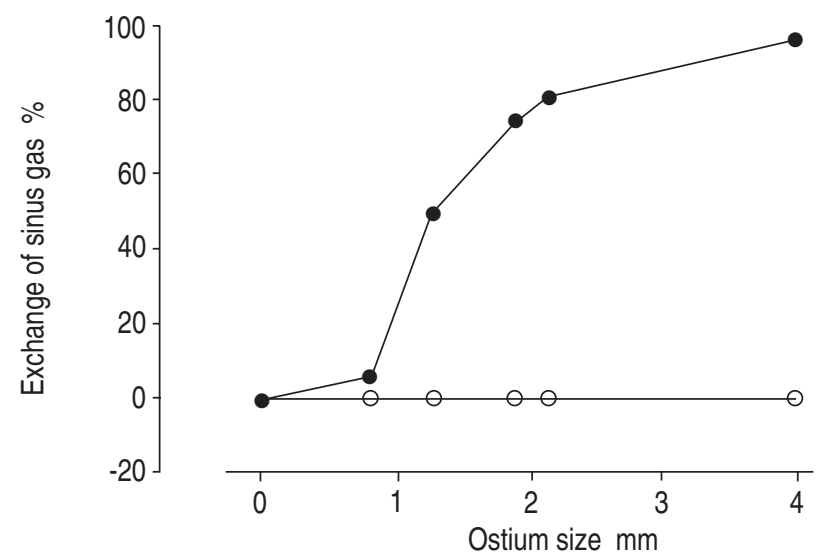

Fig. 6.- Influence of ostium size on sinus gas exchange in a sinus/ nasal model. A subject performed a single breath exhalation at a fixed flow rate $\left(0.2 \mathrm{~L} \cdot \mathrm{s}^{-1}\right)$ either silently $(\bigcirc)$ or with phonation $(\mathbf{O})$. Sinus gas exchange was calculated by measuring nitric oxide in the syringe before and immediately after each exhalation.

immediately after the exhalations (fig. 6). No significant changes in syringe NO concentrations were found after silent exhalations, regardless of ostium size. In contrast, during humming the NO exchange was strongly dependent on ostium size and reached almost $100 \%$ with the largest ostium (fig. 6).

Effect of humming frequency. Significant changes were found in NO output by modifying the frequency of humming in all experiments. When using artificial humming in the model, NO output was $230 \pm 5.7 \mathrm{~nL} \cdot \mathrm{min}^{-1}$ at a frequency of $120 \mathrm{~Hz}$, $295 \pm 3.4 \mathrm{~nL} \cdot \mathrm{min}^{-1}$ at $200 \mathrm{~Hz}$ and $143 \pm 2.0 \mathrm{~nL} \cdot \mathrm{min}^{-1}$ at $450 \mathrm{~Hz}$ $(\mathrm{p}<0.05)$

In the human humming model, NO output was $204 \pm 11 \mathrm{~nL} \cdot \mathrm{min}^{-1}$ at $130 \mathrm{~Hz}, 175 \pm 8 \mathrm{~nL} \cdot \mathrm{min}^{-1}$ at $150 \mathrm{~Hz}$ and $143 \pm 2 \mathrm{~nL} \cdot \mathrm{min}^{-1}$ at $450 \mathrm{~Hz}(\mathrm{p}<0.05, \mathrm{n}=5$, fig. 7).

When studying the effect of different humming frequencies on NO output from syringes with different resonance frequencies, it was found that the NO output was greatest when the humming frequency was close to the resonance frequency of the particular sinus (table 1).

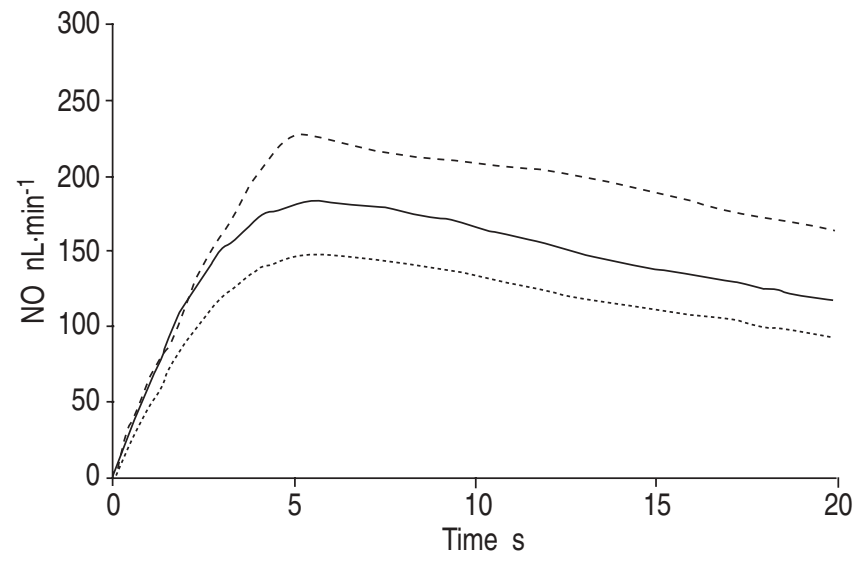

Fig. 7.-The effect of three different humming frequencies (----: $130 \mathrm{~Hz}$; - $150 \mathrm{~Hz} ; \cdots \cdots \cdot 450 \mathrm{~Hz}$ ) on nitric oxide (NO) output in a sinus/nasal model. A subject exhaled orally in the model at a fixed flow rate of $0.2 \mathrm{~L} \cdot \mathrm{s}^{-1}$, a NO concentration of $8 \mathrm{ppm}$, a resistance of $1 \mathrm{cmH}_{2} \mathrm{O}$ and an ostium size of $1.9 \mathrm{~mm}$. 
Table 1.-Effect of humming frequency on nitric oxide output $\left(\mathrm{nL} \cdot \mathrm{min}^{-1}\right)$ using sinuses with different resonance frequency in the model

\begin{tabular}{lcc}
\hline Humming frequency & \multicolumn{2}{c}{ Sinus resonance frequency } \\
\cline { 2 - 3 } & $120 \mathrm{~Hz}$ & $200 \mathrm{~Hz}$ \\
\hline $120 \mathrm{~Hz}$ & $1043 \pm 10$ & $527 \pm 5.8$ \\
$200 \mathrm{~Hz}$ & $561 \pm 8.3$ & $611 \pm 7.7$ \\
$400 \mathrm{~Hz}$ & $286 \pm 6.3$ & $418 \pm 8.1$ \\
\hline
\end{tabular}

\section{Effect of syringe volume}

Tables 2 and 3 show the result after humming when the ostial size, NO concentration, flow and resistance were kept constant according to the standard setting. Syringe volumes of $5,10,15$ and $20 \mathrm{~mL}$ were used. With a ratio for the sinus volumes of $1: 2: 3: 4$ the ratios for NO output were 1:2.5:5:7 in the artificial humming model and $1: 2: 4: 5.5$ in the human humming model.

Table 2. - The influence of sinus volume, sinus nitric oxide (NO) concentration and flow rate on resulting NO output induced by an artificial pulsating airflow in a model of the nose and sinus with artficial humming

NO output $\mathrm{nL} \cdot \mathrm{min}^{-1}$

\begin{tabular}{cc}
\hline Sinus volume $\mathrm{mL}$ & \\
5 & $79 \pm 1.0$ \\
10 & $159 \pm 4.5^{*}$ \\
15 & $295 \pm 3.4^{*}$ \\
20 & $427 \pm 3.7^{*}$ \\
NO concentration ppm & \\
2 & $76 \pm 1.5$ \\
4 & $162 \pm 2.8^{*}$ \\
8 & $295 \pm 3.4^{*}$ \\
10 & $434 \pm 6.1^{*}$ \\
Flow $\mathrm{L}^{-1}$ & \\
0.20 & $295 \pm 3.4$ \\
0.25 & $369 \pm 5.8^{*}$ \\
0.30 & $411 \pm 7.6^{*}$ \\
\hline
\end{tabular}

$*: \mathrm{p}<0.05$.

Table 3. - The influence of sinus volume, sinus nitric oxide (NO) concentration and flow rate on resulting NO output induced by human pulsating airflow in a model of the nose and sinus with human humming

NO output $\mathrm{nL} \cdot \mathrm{min}^{-1}$

\begin{tabular}{cc}
\hline Sinus volume $\mathrm{mL}$ & \\
5 & $79 \pm 1.0$ \\
10 & $87 \pm 3.6^{*}$ \\
15 & $175 \pm 8.0^{*}$ \\
20 & $242 \pm 14.7^{*}$ \\
NO concentration ppm & \\
2 & $57 \pm 8.1$ \\
4 & $118 \pm 14.6^{*}$ \\
8 & $175 \pm 8.0^{*}$ \\
10 & $416 \pm 32^{*}$ \\
Flow $\mathrm{L} \cdot \mathrm{s}^{-1}$ & \\
0.20 & $175 \pm 8.0$ \\
0.25 & $268 \pm 4.8^{*}$ \\
0.30 & $356 \pm 10^{*}$ \\
\hline
\end{tabular}

*: $\mathrm{p}<0.05$.

\section{Effect of syringe nitric oxide concentration}

Tables 2 and 3 show the effect of syringe NO concentration during humming. NO concentrations of $2,4,8$ and $10 \mathrm{ppm}$ were used. With a ratio for the syringe NO concentration of $1: 2: 4: 5$ the ratios for NO output in the artificial and human humming models were respectively $1: 2.1: 4: 5.5$ and 1:2:3:7.

\section{Effect of air flow rate}

Results concerning NO output at different nasal flow rates during humming are shown in tables 2 and 3. With a ratio for the flow rate of $1: 1.25: 1.5$ the ratios for NO output in the artificial and human humming models were 1:1.25:1.4 and $1: 1.5: 2$, respectively.

\section{Effect of pressure}

In the artificial humming model, an increase in NO output with higher pressure during humming (from $175 \pm 8 \mathrm{~nL} \cdot \mathrm{min}^{-1}$ to $377 \pm 22 \mathrm{~nL} \cdot \mathrm{min}^{-1}$ ) was found. In the human humming model, a reduction was found as the pressure was increased (from $250 \pm 3.4 \mathrm{~nL} \cdot \mathrm{min}^{-1}$ to $140 \pm 1.9 \mathrm{~nL} \cdot \mathrm{min}^{-1}$ ).

\section{Discussion}

In this study the authors have characterised the large and reproducible increase in nasal NO output caused by humming in healthy volunteers, as well as in a model of the nose and sinus. It was found that the humming method could add relevant information about the relative contribution of NO from the nose and sinus, as well as ostium patency. Several factors indicate that the NO increase seen during humming is mainly due to a rapid washout of NO accumulated in the paranasal sinuses. The profiles of the nasal exhalation curves (peak and progressive decline) in the model and in the human studies were very similar and the factors influencing NO output were identical. Both the peak and the total nasal NO output were markedly decreased following repeated consecutive humming manoeuvres but a complete recovery was observed after a 3-min period of silence. This pattern fits well with the notion that humming empties the sinuses and that a period of silence will allow for NO to accumulate again. In addition, as shown very recently in patients with nasal polyposis and complete sinuses obstruction [16], single-breath humming was completely ineffective in producing an increase in NO output. One cannot exclude the fact that humming could increase NO output from other sources of NO in the main nasal airways. However, oral NO output did not increase during humming in this or an earlier study [11], indicating that pulsating sound waves do not increase NO diffusion from NO-generating respiratory epithelial surfaces in general. In addition, a NO synthase inhibitor (L-NAME) applied locally in the nose reduced silent nasal NO output by $50 \%$ but had no effect on the increase during humming. Assuming that this route of administration mostly affects the nasal mucosa with less penetration into sinuses, this argues against a major contribution from the nasal mucosa to the NO increase seen during humming.

Some of the factors that may influence the rate of air exchange between the sinuses and the nose have been studied here. The model parameters were chosen because they resemble physiological values [6,7], although it is impossible to define a normal nasal cavity and paranasal sinus since the anatomical and physiological variations are almost unlimited. 
The normal volume of the maxillary sinus is considered to be $\sim 15 \mathrm{~mL}$, ranging 2-30 $\mathrm{mL}$ [17], and the NO concentrations in the paranasal sinuses are variable, ranging 5->20 ppm [5]. The normal diameter of the maxillary ostium is $\sim 2 \mathrm{~mm}$ but may vary between $0.5-5 \mathrm{~mm}$ [6]. Finally, the respiratory pressure in the paranasal sinuses is similar to that in the nose when the ostia are patent and amounts to $\sim 1 \mathrm{cmH}_{2} \mathrm{O}$ [6]. Earlier studies have shown that ostium size is the most important factor determining sinus ventilation [6, 7, 10, 17], which is also influenced by airflow rate, airway pressure and sinus volume. In the present study all these factors affected the increase in nasal NO during humming and, again, ostium size seemed to be the most important. In addition, sinus NO concentrations and humming frequency also affected sinus ventilation.

Interestingly, the humming frequency affected sinus output both in the model and in the healthy volunteers. The reason for this is not entirely clear at this stage. It is likely that the individual shape of the sinus and the nose will determine at which frequency the maximal ventilation of the sinuses will occur. Every cavity has a specific resonance frequency, which can be calculated from its shape and size. In preliminary experiments the authors have shown that the ventilation of the sinus in the model is greatest when the humming frequency is close to the resonance frequency of the sinus model.

It should be considered that the model presented here does not mimic the continuous NO production occurring normally in the human sinuses [5] and the complex dynamics of production and absorption from nasal airway mucosa [18, 19]. Moreover, the sinus ostium diameter could not be directly measured in the healthy subjects. Another obvious methodological problem is the fact that changes in syringe volume in the model will automatically change the resonance frequency of the system. For this reason it is somewhat difficult to separately pinpoint the importance of volume in the model used.

The experiments looking at remaining NO in the syringe after single-breath exhalations indicate that humming is an enormously effective means of increasing sinus ventilation. This is also supported by the in vivo experiments, where the rapid decline in NO during humming indicated sinus emptying. Previous work has shown that the time needed to exchange all gas in the sinuses varies between $\sim 5$ min up to $1 \mathrm{~h}[10,17]$, with much longer time needed in patients with sinus disorders [10]. The current results indicate that almost the entire sinus volume is exchanged in one single exhalation if the subject is humming. Even when using a small ostial diameter, humming was very effective at increasing NO exchange in the sinus model. This suggests that humming could help to increase sinus ventilation in patients with sinusitis and partly obstructed ostia. Whether this would be beneficial in treatment or prevention of sinusitis remains to be studied. Nevertheless, it is interesting that medical, as well as surgical, treatment of chronic sinusitis generally aims to increase sinus ventilation, which is often impaired in this disorder.

There has been much discussion on the anatomical origin of nasal NO. A great deal of NO is produced in the sinuses [5], but the contribution of sinus NO to that found in the nasal cavity is somewhat unclear. Some authors have claimed that sinus NO is the major source of nasal NO $[5,20,21]$, while others believe the contribution from the sinuses is of minor importance [22]. In the present study, silent nasal NO output was between 5-50\% lower immediately after repeated humming. If the assumption is made that the sinuses are effectively emptied by this manoeuvre, the decrease should fairly well reflect the normal contribution from the sinuses to NO found in nasally exhaled air. It is, however, important to note that this assumption may only be true under the exact conditions of this study. For example, at a different flow rate the relative contribution from the sinuses and nose may differ and the sinus contribution seems to be larger during inhalation compared to exhalation [23]. Nevertheless, using the methods described here, it may be possible to better separate sinus NO from nasal mucosal NO release. Thus, the large peak seen during humming is probably predominantly of a sinus origin whereas the nasal mucosa contributes relatively more during silent nasal exhalations.

Measurements of nasal NO could be useful in the clinic in diagnosis and therapy monitoring of respiratory disorders. For example, nasal NO is extremely low in primary ciliary dyskinesia (PCD) [4] and in cystic fibrosis [24]. In fact, a nasal NO test is currently part of the clinical routine at the national centre for PCD in the UK [25]. In allergic rhinitis the picture is less clear. Some groups have shown an increase in nasal NO in rhinitis [26-28], while others find normal values in these patients $[24,29,30]$. The reason for the discrepancies in studies on rhinitis is probably related to methodology. In addition, the high background levels of NO in the nose could easily blunt subtle alterations in NO production. By combined nasal NO measurements with or without humming it may be possible to better estimate NO output from the nasal mucosa, e.g. in rhinitis. A suggested method could be to start with repeated humming manoeuvres to empty the sinuses, immediately followed by a silent nasal exhalation along with NO measurements. In this way the sinus contribution to nasally exhaled NO could be minimised, which could help to unmask changes in nasal mucosal NO output.

Another possible way of using the humming test would be in estimating sinus ostial patency, as suggested recently [11]. Blockage of the ostium is a key event in the pathogenesis of sinusitis $[6,8,9,31,32]$ and an easy test that could reveal this could be useful in the clinic. In the current study it was found that the ostium size was a major determinant of the NO increase seen during humming. Indeed, in the model, a fivefold increase in ostium diameter corresponded to a 30 -fold increase in NO output during humming. In further support of this, the present authors recently showed that the humminginduced increase in nasal NO output is completely absent in patients with nasal polyposis and obstructed sinus ostia [16]. The exact procedure to be used in NO measurements for estimation of ostial size in vivo remains to be explored. In a future attempt to standardise these measurements, factors such as exhalation flow rate, humming frequency and effects of repeated exhalations need to be taken into account. In addition, it needs to be established whether a person should keep the nasal cavity completely nonventilated using a noseclip prior to the exhalation.

In conclusion, single-breath humming causes a great and reproducible increase in nasal nitric oxide output in healthy subjects. This increase is dependent on factors that modify sinus ventilation, where sinus ostium size is the most significant. Combined nasal nitric oxide measurement with or without humming may be a useful noninvasive tool in exploring sinus ventilation as well as nasal mucosal nitric oxide output.

\section{References}

1. Gustafsson LE, Leone AM, Persson MG, Wiklund NP, Moncada S. Endogenous nitric oxide is present in the exhaled air of rabbits, guinea pigs and humans. Biochem Biophys Res Commun 1991; 181: 852-857.

2. Alving K, Weitzberg E, Lundberg JM. Increased amount of 
nitric oxide in exhaled air of asthmatics. Eur Respir J 1993; 6: $1368-1370$.

3. Gerlach H, Rossiant R, Pappert D, Knorr M, Falke KJ. Auto-inhalation of nitric oxide after endogenous synthesis in the nasopharynx. Lancet 1994; 343: 518-519.

4. Lundberg JO, Weitzberg E, Nordvall SL, Kuylenstierna R, Lundberg JM, Alving K. Primarily nasal origin of exhaled nitric oxide and absence in Kartagener's syndrome. Eur Respir J 1994; 7: 1501-1504.

5. Lundberg JO, Farkas-Szallasi T, Weitzberg E, et al. High nitric oxide production in human paranasal sinuses. Nat Med 1995; 1: 370-373.

6. Aust R, Drettner B. The functional size of the human maxillary ostium in vivo. Acta Otolaryngol 1975; 78: 432-435.

7. Paulsson B, Dolata J, Lindberg S, Ohlin P. Factors influencing 133-xenon washout in a nose-sinus model. Clin Physiol 2001; 21: 246-252.

8. Kaliner MA, Osguthorpe JD, Fireman P, et al. Sinusitis: bench to bedside: current findings, future directions. J Allergy Clin Immunol 1997; 99: S829-S848.

9. Wagenmann M, Naclerio RM. Anatomic and physiologic considerations in sinusitis. J Allergy Clin Immunol 1992; 90: 419-423.

10. Paulsson B, Dolata J, Larsson I, Ohlin P, Lindberg S. Paranasal sinus ventilation in healthy subjects and in patients with sinus disease evaluated with the 133 -xenon washout technique. Ann Otol Rhinol Laryngol 2001; 110: 667-674.

11. Weitzberg E, Lundberg JO. Humming greatly increases nasal nitric oxide. Am J Crit Care Med 2002; 166: 144-145.

12. Durrant JD, Lovrinic JH. Bases of Hearing Science, 3rd Ed. Williams and Wilkins, Baltimore, 1995: p. 60.

13. American Thoracic Society. Recommendations for standardized procedures for the online and offline measurement of exhaled lower respiratory nitric oxide and nasal nitric oxide in adults and children. Am J Respir Crit Care Med 1999; 160: 2104-2117.

14. Lundberg JO, Weitzberg E. Nasal nitric oxide in man. Thorax 1999; 54: 947-952.

15. Palm JP, Graf P, Lundberg JO, Alving K. Characterization of exhaled nitric oxide: introducing a new reproducible method for nasal nitric oxide measurement. Eur Respir $J$ 2000; 16: 236-241.

16. Lundberg JO, Maniscalco M, Sofia M, Lundblad L, Weitzberg E. Humming, nitric oxide and paranasal sinus obstruction. JAMA 2003; 289: 302-303.

17. Aust R, Drettner B. Experimental studies of the gas exchange through the ostium of the maxillary sinus. Upsala J Med Sci 1974; 79: 177-186.
18. Chambers DC, Carpenter DA, Ayres JG. Exchange dynamics of nitric oxide in the human nose. J Appl Physiol 2001; 91: 1924-1930.

19. DuBois AB, Douglas JS, Stitt JT, Mohsenin V. Production and absorption of nitric oxide gas in the nose. $J$ Appl Physiol 1998; 84: 1217-1224.

20. Arnal JF, Flores P, Rami J, et al. Nasal nitric oxide concentration in paranasal sinus inflammatory diseases. Eur Respir J 1999; 13: 307-312.

21. Lewandowski $\mathrm{K}$, Busch $\mathrm{T}$, Lohbrunner $\mathrm{H}$, et al. Low nitric oxide concentrations in exhaled gas and nasal airways of mammals without paranasal sinuses. $J$ Appl Physiol 1998; 85: 405-410.

22. Haight JS, Djupesland PG, Qjan W, et al. Does nasal nitric oxide come from the sinuses? J Otolaryngol 1999; 28: 197204.

23. Tornberg DC, Marteus H, Schedin U, Alving K, Lundberg JO, Weitzberg E. Nasal and oral contribution to inhaled and exhaled nitric oxide: a study in tracheotomized patients. Eur Respir J 2002; 19: 859-864.

24. Lundberg JO, Nordvall SL, Weitzberg E, Kollberg H, Alving $\mathrm{K}$. Exhaled nitric oxide in paediatric asthma and cystic fibrosis. Arch Dis Child 1996; 75: 323-326.

25. Narang I, Ersu R, Wilson NM, Bush A. Nitric oxide in chronic airway inflammation in children: diagnostic use and pathophysiological significance. Thorax 2002; 57: 586-589.

26. Arnal JF, Didier A, Rami J, et al. Nasal nitric oxide is increased in allergic rhinitis. Clin Exp Allergy 1996; 27: 358-362.

27. Kharitonov SA, Rajakulasingam K, O'Connor B, Durham $\mathrm{SR}$, Barnes PJ. Nasal nitric oxide is increased in patients with asthma and allergic rhinitis and may be modulated by nasal glucocorticoids. J Allergy Clin Immunol 1997; 99: 58-64.

28. Martin U, Briden K, Devoy M, Howarth P. Increased levels of exhaled nitric oxide during nasal and oral breathing in subjects with seasonal rhinitis. J Allergy Clin Immunol 1996; 97: 768-772.

29. Henriksen AH, Sue-Chu M, Lingaas Holmen T, Langhammer A, Bjermer L. Exhaled and nasal NO levels in allergic rhinitis: relation to sensitization, pollen season and bronchial hyperresponsiveness. Eur Respir J 1999; 13: 301-306.

30. Maniscalco M, Sofia M, Carratu L, Higenbottam T. Effect of nitric oxide inhibition on nasal airway resistance after nasal allergen challange in allergic rhinitis. Eur J Clin Invest 2001; 31: 462-466.

31. Hamilos DL. Chronic sinusitis. J Allergy Clin Immunol 2000; 106: 213-227.

32. Senior BA, Kennedy DW. Management of sinusitis in the asthmatic patient. Ann Allergy Asthma Immunol 1996; 77: 6-19. 